\title{
POESIA, ARTE E TECNOLOGIA: UM DIÁLOGO COM A IMAGEM DO AMOR EM SEBASTIÃO NUNES
}

\author{
André Araujo de Menezes* \\ Wagner José Moreira*
}

\begin{abstract}
RESUMO: Este artigo se propõe refletir sobre o processo criativo a partir das relações entre a linguagem verbal e a não verbal no contexto dos diálogos poéticos entre artes plásticas e poesia e de um pensamento sobre a intermidialidade, considerando-se aí as traduções intersemióticas, que nos permitem discutir aspectos também das tecnologias. Para tanto, escolhemos como objeto de estudo a imagem do amor na poesia de Sebastião Nunes, especificamente o livro Antologias Mamalucas.
\end{abstract}

Palavras-chave: Artes plásticas. Poesia. Intermidialidade.

As relações entre poesia e pintura datam da Antiguidade greco-latina e percorrem toda a história, pois o homem sempre se interessou em descrever quadros com a linguagem verbal e pintar quadros baseados em poesia. Porém, no princípio, essa relação poesia/pintura era usada para mostrar a superioridade de uma arte sobre a outra. Ora a poesia era considerada a arte superior, ora a pintura mostrava maior domínio sobre a poesia. Mas se ambas as artes têm o poder de interagir é porque há uma relação que as liga, que as completa. Em busca de se compreender essa relação implícita, tornam-se cada vez mais frequentes os estudos dirigidos à intermidialidade especialmente na área tradicionalmente chamada de Estudos Interartes.

Assim, na abordagem dessa questão, e para melhor podermos analisar tais fenômenos transposicionais entre diferentes mídias, utilizamos três linhas

\footnotetext{
Artista plástico; mestre em Estudos de Linguagens pelo Centro Federal de Educação Tecnológica de Minas Gerais, Belo Horizonte, Brasil. Imeio: andre@alfavaca.com.br

Poeta; doutor em Literatura pela PUCMINAS; Professor do Centro Federal de Educação Tecnológica de Minas Gerais, Belo Horizonte, Brasil. Imeio: wgnris@gmail.com
}

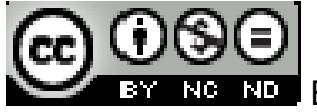

Texto Digital, Florianópolis, v. 10, n. 1, p. 221-248, jan./jul. 2014. ISSNe: 1807-9288 
metodológicas que interagiram entre si: a Literatura Comparada, a Tradução Intersemiótica e a Pesquisa em Artes. Para tanto, considerando a obra de Sebastião Nunes, permeada de humor e apropriações de linguagem numa tradição intersemiótica, pudemos situar seus trabalhos nos campos comparativos de análise, contextualizando-os no cenário da contracultura e ressaltando a questão do amor nas suas categorias e teorias.

Utilizamos ainda a teoria da Tradução Intersemiótica de Julio Plaza a fim de reconhecer os diálogos entre as diferentes linguagens, e assim promover o processo de recriação das formas estéticas em transmutações da linguagem verbal para o universo das artes visuais.

Por fim, seguindo os conceitos da Pesquisa em Artes, desenvolvemos uma série pictórica composta por pintura, desenho e vídeo animação, que culminou em uma exposição suplementando a análise e com a prática da recriação e da transposição da poesia para as artes plásticas.

\section{A imagem do amor}

Para identificarmos a imagem do amor na poesia de Sebastião, utilizamos os estudos das categorias do amor com base nos escritos de autores como Bataille, Barthes e Octavio Paz.

A imagem do amor está intimamente ligada à produção poética na história da humanidade. Em todas as épocas o homem abordou o amor, o erotismo e o sexo, seja na poesia, na pintura, no teatro ou na música. Para Octávio Paz, a relação entre erotismo e poesia é tão estreita que podemos, com ele, dizer que o erotismo é uma poética corporal e que a poesia é uma erótica verbal. A partir dessa afirmativa podemos identificar uma relação intermidiática entre os objetos que caracterizam esta pesquisa: poesia, artes plásticas e erotismo. 
Cada poeta, cada pintor, expressa o amor de forma singular, afinal a temática do amor é tão íntima como a vivência do amor. Essa imagem, no decorrer dos tempos, passou por diferentes significações, desde relações divinas e diretamente ligadas à reprodução humana e à fertilidade, até como forma de transgressão social. Faz-se necessário distinguir sexo, erotismo e amor. O sexo está ligado à imagem de reprodução, de continuidade. O erotismo é uma invenção do homem, é o que nos diferencia dos outros animais. O erotismo, então, segundo Bataille, é a transgressão por excelência "dado que ele é resultado da atividade sexual humana enquanto prazer e, ao mesmo tempo, consciência do interdito" (BATAILLE, 1987, p.3). Nunes vem de uma tradição de contracultura, na qual a transgressão faz parte de seus procedimentos com 0 intuito de ruptura do modus vivendi e na maioria das vezes, esta transgressão é utilizada na forma de tema no qual o sexo e o erotismo é exposto como forma de chocar o público e questionar certos tabus da sociedade.

Nas décadas de 1960 e 1970 mulheres queimaram sutiãs em praça pública em protesto contra o machismo. Pregava-se o amor livre e uma revolução sexual se instalava. Era a contracultura que se estabelecia como uma nova ordem. Temas como homossexualismo, bissexualismo, orgulho negro, 0 uso do anticoncepcional, a independência feminina, nunca antes estiveram tão em voga como neste momento. Houve um grande interesse pela psicanálise e diversos estudos sobre a sexualidade humana como os Relatórios Kinsey com $\mathrm{O}$ Comportamento Sexual do Macho Humano e O comportamento Sexual da Fêmea Humana e o Relatório Hite.

\footnotetext{
O relatório Hite sobre a sexualidade feminina obteve repercussão ao divulgar, através de relatos das próprias mulheres, a extraordinária capacidade orgástica clitoriana e a ênfase na masturbação como fonte de satisfação sexual, fato já levantado por Kinsey, mas muito explorado e valorizado por Hite. (SENA, 2008, p. 1)
}

A sexualidade, o erotismo e a pornografia foram temas usados na contracultura como forma de transgressão, autoconhecimento e provocação. Assim é que a 
própria juventude foi buscar o direito à liberdade nos escritos e ensinamentos de pensadores como Herbert Marcuse (Eros e Civilização), Wilhelm Reich ( $A$ Revolução Sexual dos Jovens), Jean-Paul Sartre, Michel Foucault e os professores Timothy Leary, Alan Watts, entre outros.

Na poesia marginal há uma opção clara pela linguagem chula e pelo uso de palavras de baixo calão, do escatológico e do abjeto, e pelas imagens de cunho neonaturalista na configuração dos poemas. Um texto com uma carga de deboche um uivo lírico que não se preocupava em buscar belas palavras para se expressar e sim palavras grotescas para expressar o amor e o erotismo.

Podemos pensar que esse sentido grotesco e as palavras grosseiras têm uma função transgressora na obra de Sebastião Nunes. E podemos concluir também que isso é uma característica comum aos poetas marginais, herdeiros dos beatniks.

As palavras grosseiras que designam os órgãos, os produtos ou os atos sexuais introduzem o mesmo rebaixamento. Essas palavras são interditos, pois geralmente é proibido nomear esses órgãos. Nomeá-los de uma maneira desabrida faz passar da transgressão à indiferença que põe num mesmo plano o profano e o mais sagrado. (BATAILLE, 1987, p.89)

Ao colocar no mesmo plano o lírico e o tosco, o profano e o sagrado, Nunes cria uma tensão de linguagem capaz de despertar um estranhamento no leitor menos afeiçoado com esses interditos sexuais. Essas interdições sexuais aparecem por toda a história da humanidade. Desde as sociedades da préhistória vemos vestígios de restrições a comportamentos sexuais. (Cf. BATAILLE, 1987, p.21). Os poetas ditos marginais sempre usaram esses interditos como forma de transgressão ao modus vivendi de sua época. Artistas de todos os campos, desde os tempos remotos, abordaram esses temas e linguagens em que interditos sexuais são colocados à luz.

Selecionamos um poema - "Canção desajeitada" - de Nunes, que consideramos mais significativo para a temática do amor. Em seguida propomos

Texto Digital, Florianópolis, v. 10, n. 1, p. 221-248, jan./jul. 2014. ISSNe: 1807-9288 
uma tradução criativa desses poemas para a linguagem visual. Além do intuito de identificar a potência do fenômeno tradutológico e suas características, buscamos também conhecer os fundamentos da Tradução Intersemiótica, com base nos estudos de Julio Plaza.

\section{Tradução}

A ideia de tradução está intimamente ligada à noção de representatividade. $O$ objeto traduzido jamais será o objeto original em sua plenitude. Isso nos põe a pensar que a tradução não é uma mera transferência de significados e sim um processo de recriação.

Para melhor nos aprofundarmos na tradução intersemiótica, é necessário que saibamos sobre a equivalência tradutória que ocorre no processo recriador que sustenta a tradução criativa, ou tradução intersemiótica, e recorremos a Julio Plaza. Segundo o autor, temos três tipos de equivalência tradutória:

1- Equivalência imagética: que é a transposição do mesmo para outro meio, como é o caso das fotografias e retratos pintados;

2- Equivalência diagramática: esta tradução criativa não visa à fidelidade semântica, e não busca assemelhar-se ao seu objeto nas aparências, mas o representa graficamente como, por exemplo, o ideograma;

3- Equivalência metafórica: é a semelhança através de símbolos conotativos presentes na tradução. Esse tipo de equivalência é muito comum em traduções simbólicas visto que há uma relação estreita entre metáfora e símbolo. As equivalências não são excludentes entre si, e em uma mesma tradução pode haver incidências de mais de uma equivalência. Porém, pode haver dominância de uma equivalência sobre as outras. 
Através dos estudos e das práticas de Tradução Intersemiótica, constatamos a importância da influência do meio na tradução, já que o meio ou o suporte em que essa tradução é realizada lhe empresta tanto sua aparência e seus procedimentos quanto sua historicidade.

Plaza classificou os meios de produção tradutológicos em 3 categorias: artesanais, mecânicos e eletrônicos. E cada meio, como podemos observar, dáse de forma diferente no que diz respeito a sua reprodutibilidade, regime de produção e regime de recepção. Os meios artesanais geram imagens de primeira geração, de caráter único, cujo regime de produção é o analógico (desenho, pintura, etc.) e cujo regime de recepção, em relação ao expectador, é o valor de culto. Os meios mecânicos geram imagens de segunda geração, imagens técnicas de caráter reprodutível cujo regime de produção é o analógico/digital (gravura, fotografia, cinema, vídeo), e o regime de recepção é o valor de exposição. $\mathrm{E}$ os meios eletrônicos geram imagens de terceira geração que são realizadas por computador com a ajuda de programas numéricos ou de tratamento digital e sem o auxílio de referentes externos. Essas imagens em disponibilidade permanente, em matrizes-memórias numérico magnéticas, inauguram uma nova forma de reprodutibilidade, cujo regime de recepção é o valor de recriação.

Para acrescentar novos elementos a essa discussão, passemos ao poema "Canção desajeitada" de Sebastião Nunes: 


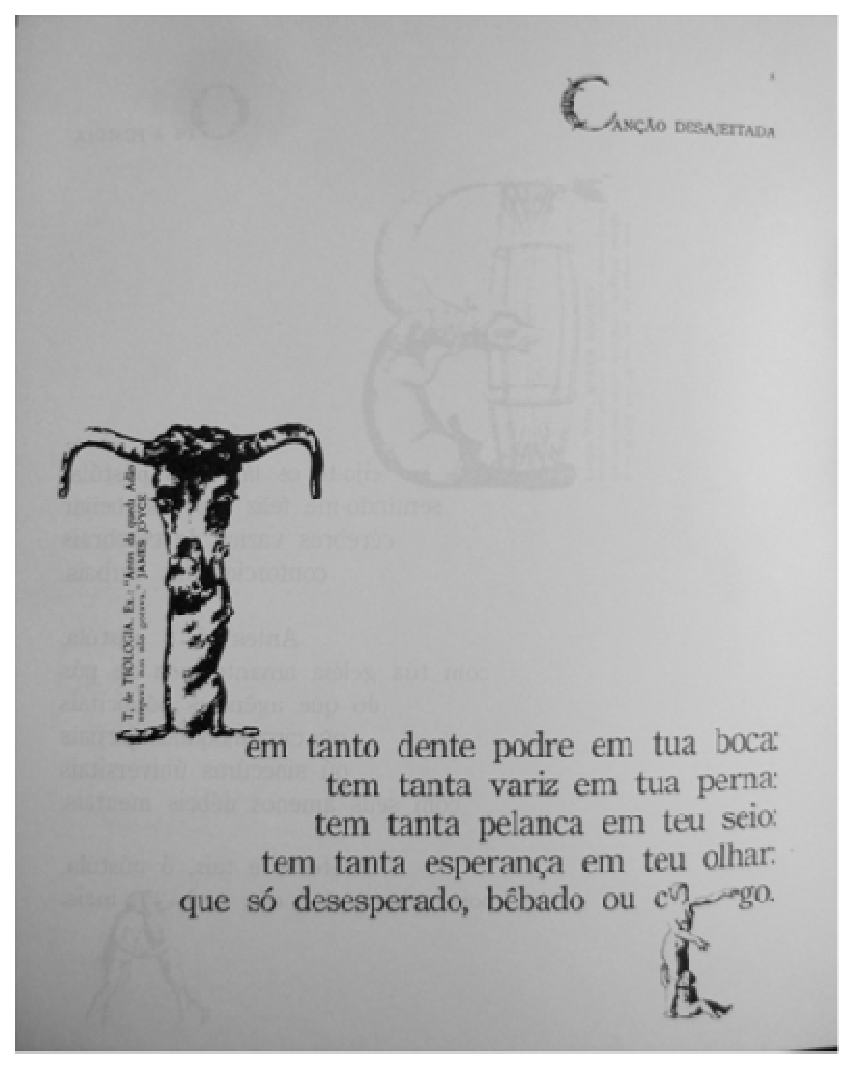

Fig. 01

Para levar a cabo o processo tradutório, de recriação a partir desse poema, foi importante o processo de sua análise, a qual nos provocou os primeiros insights suscitados de uma observação cuidadosa do texto e das imagens do poema, visto que se trata de um poema híbrido: visual e verbal. Em um caderno de esboços foram anotadas todas as sensações possíveis emanadas do poema. Nese momento torna-se crucial abrir as percepções para a multiplicidade de possibilidades levando em consideração os limites rompidos pela arte contemporânea e trabalhar com a existência de um pensamento visual estruturado de forma verbal. Icleia Borsa Cattani em seu texto "Arte contemporânea: O lugar da pesquisa" nos alerta para a importância do verbalizar no caso da pesquisa em artes:

É, no entanto, necessário enfatizar mais uma vez que os mecanismos do pensamento visual não são os mesmos que regem a função linguística. $O$

Texto Digital, Florianópolis, v. 10, n. 1, p. 221-248, jan./jul. 2014. ISSNe: 1807-9288 
artista tem que manipular dois sistemas de pensamentos distintos, que resultam em duas produções distintas. Metodologicamente, portanto, é importante que ele trabalhe simultaneamente com os dois sistemas de pensamento, consignando suas intenções, suas dúvidas, seus processos criativos no que se chamaria de "diário de bordo", durante a elaboração do seu trabalho artístico. (CATTANI apud BLANCA; TESSLER, 2002, p.41)

E foi com esse pensamento que a pesquisa prosseguiu, começando pelas anotações das fruições visuais do poema nesse diário de bordo e, concomitantemente, produzindo textualmente as impressões dessa produção visual. Este é o momento em que a obra começa a se instaurar. Podemos observar na figura 2 que tais esboços emanam de imagens preexistentes e que compõem um atlas de imagens, como um arquivo imagético de imagens dos mais diferentes fontes, tais como: fotos de jornais e revistas, fotografias pessoais, cenas de filmes, pinturas da história da arte, sites pornográficos, etc.

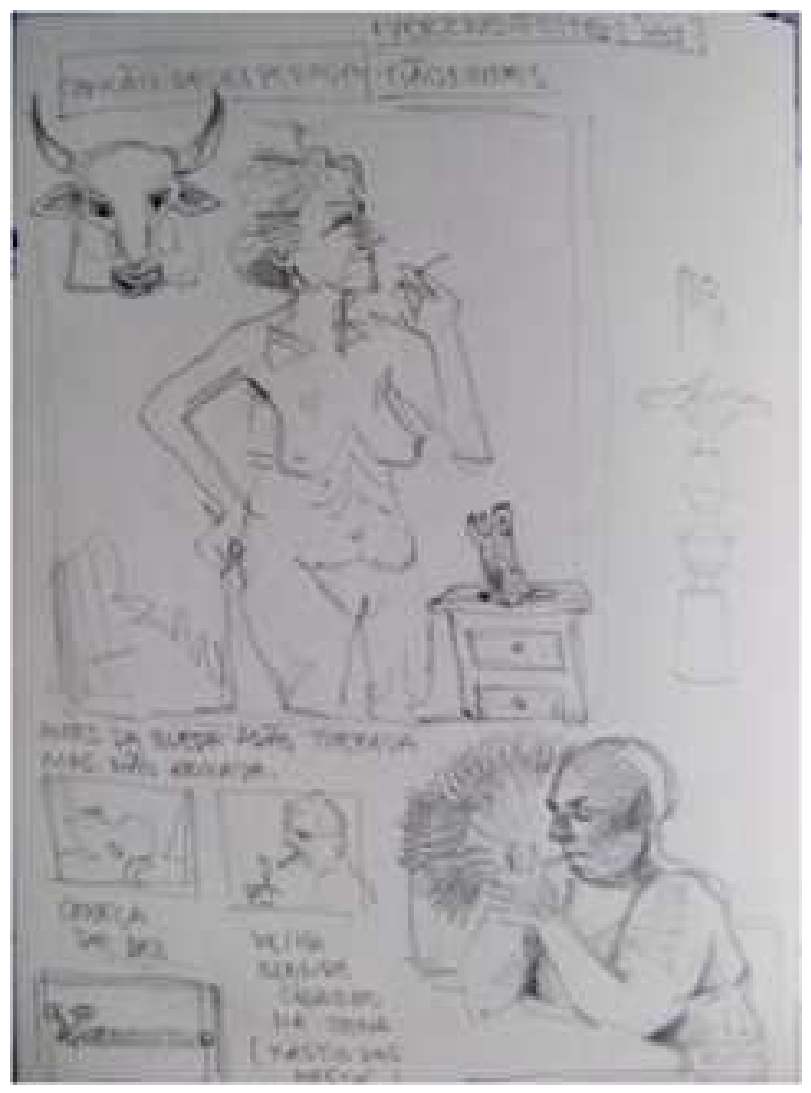

Fig. 02

Texto Digital, Florianópolis, v. 10, n. 1, p. 221-248, jan./jul. 2014. ISSNe: 1807-9288 
Outra questão deve ser levada em conta nesse processo, a que a professora Sandra Rey destaca em "Por uma abordagem metodológica da pesquisa em artes", quando afirma que a obra se instaura em três momentos/dimensões distintas, que se entrelaçam:

\begin{abstract}
A primeira dimensão, abstrata, processa-se no nível do pensamento e revela-se na forma de ideias, de esboços, muitas vezes sem grandes intenções, em algumas anotações improvisadas ou em projetos mais elaborados, que poderão, ou não, se concretizar em obras. Num segundo plano, temos a dimensão da prática feita de procedimentos, manipulações técnicas ou operacionais, reações de materiais ou substâncias assim como o estabelecimento de interfaces com os mais avançados processos tecnológicos. E, num terceiro nível [...] a obra em processo conecta-se com tudo o que diz respeito ao conhecimento. [...] A obra em processo de formação insere-se de maneira específica, algumas vezes peculiar, numa discussão proposta pela produção contemporânea e/ou pela História da Arte. (BLANCA; TESSLER, 2002, p.126)
\end{abstract}

Assim, as imagens sugeridas em uma tradução são imagens que vem tanto de uma tradução direta quanto de imagens coletadas na memória do tradutor. Isto é, a nossa memória visual, ou memória estética.

Considerados esses aspectos, e depois das anotações no caderno de esboços uma coleção de fotografias, foi montado um arquivo imagético de referências (fig 4). Essas imagens estão à disposição para nos ajudar nas criações, e a maioria das fotos sofre mutações e cortes ao serem incorporadas em uma tradução criativa. Segundo Sandra Rey:

as teorias sobre fotografia mostram o quanto os objetos e sua representação se encontram interligados. E ao mesmo tempo definitivamente separados devido ao seu dispositivo técnico que determina esse corte entre o real e a realidade da foto. (REY, 2010).

A intenção nesse procedimento é apropriarmos de uma fotografia já existente ou fotografada por nós mesmos, fazer um deslocamento do seu contexto em que a foto foi tirada e resignificar essa imagem em outro contexto. Utilizando os recursos de um editor de imagens no computador, recortamos essa foto, 
invertemos suas partes, saturamos suas cores, mudamos os personagens de cenário, assim, construímos certo distanciamento do real e aproximamos do âmbito da ficção. E mais adiante ao citar Pierce, Sandra Rey ressalta que:

\begin{abstract}
a foto é um híbrido, isto é, um índice no processo de instauração e um ícone em sua configuração, em suas relações com a semelhança, com o motivo, enquanto produto acabado; de modo que a foto importada no computador se torna uma imagem virtual, uma fina camada de dados icônicos sobre os quais se pode intervir: material para fazer arte. (REY, 2010).
\end{abstract}

A proposta dessa pesquisa foi justamente coletar material poético visual, e usar esse material visual em uma ressignificação poética ou reescrita criativa. Foi criado um banco de imagens que podemos chamar de "Atlas", composto por imagens coletadas via câmera fotográfica, diretamente de um objeto real e fotografado por nós, e composto por imagens coletadas dos mais variados lugares como sites pornográficos, publicidade, jornais, revistas e até cenas de filmes. Na produção das fotos de nossa autoria, durante a pesquisa, não houve nenhuma intenção de fazer fotos artísticas, prontas e acabadas. São fotos feitas sem a pretensão de acertar, ou seja, muitas foram tiradas ao acaso, muitas vezes sem nem olhar o visor. São materiais imagéticos coletados que depois, no atelier, são analisadas e ressignificadas dentro do contexto da produção imagética proposta na pesquisa.

A seguir, no atelier, as imagens coletadas foram descarregadas em um computador e retrabalhadas de acordo com a necessidade criativa. Muitos personagens descobertos nessas fotos geralmente estão em segundo plano e quando reenquadrados são trazidos para o primeiro plano. Essas imagens, ao existirem em um ambiente virtual, no caso o computador, foram submetidas aos mais variados tratamentos no programa Photoshop. E assim, ao serem inseridas em outro contexto, tornam-se outra coisa, transmutam-se, tornam-se o que o artista quiser. Afinal, os "dados do real são contaminados pelos tratamentos 
digitais e esses tratamentos jogam essas imagens para o lado da fiç̧ão." (REY, 2010).

$\mathrm{Na}$ figura 02, podemos observar a primeira fase do processo tradutório utilizado nessa reescrita. Notemos a multiplicidade de ideias vindas com a primeira impressão do poema. Notemos também que durante esse brainstorm (tempestade de ideias) as técnicas sugeridas já vão sendo anotadas.

A partir desses esboços surgiu a ideia da utilização de 3 suportes diferentes:

1- pintura: a imagem da mulher,

2- colagem digital traduzindo a citação "Durante a queda Adão trepava mas não gozava"

3- animação: a imagem da mulher acendendo um cigarro (com a referência do filme "Baixio das Bestas" de Cláudio Assis).

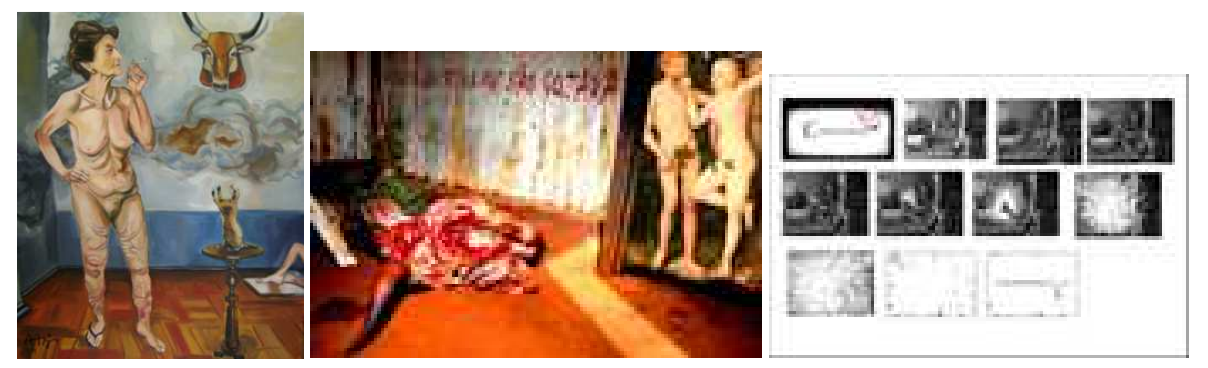

Fig. 3 - 1 - pintura 2 - colagem digital 3 - vídeo animação

\section{Primeira tradução canção desajeitada - pintura}

A seguir podemos observar as imagens usadas na primeira tradução - a pintura : 


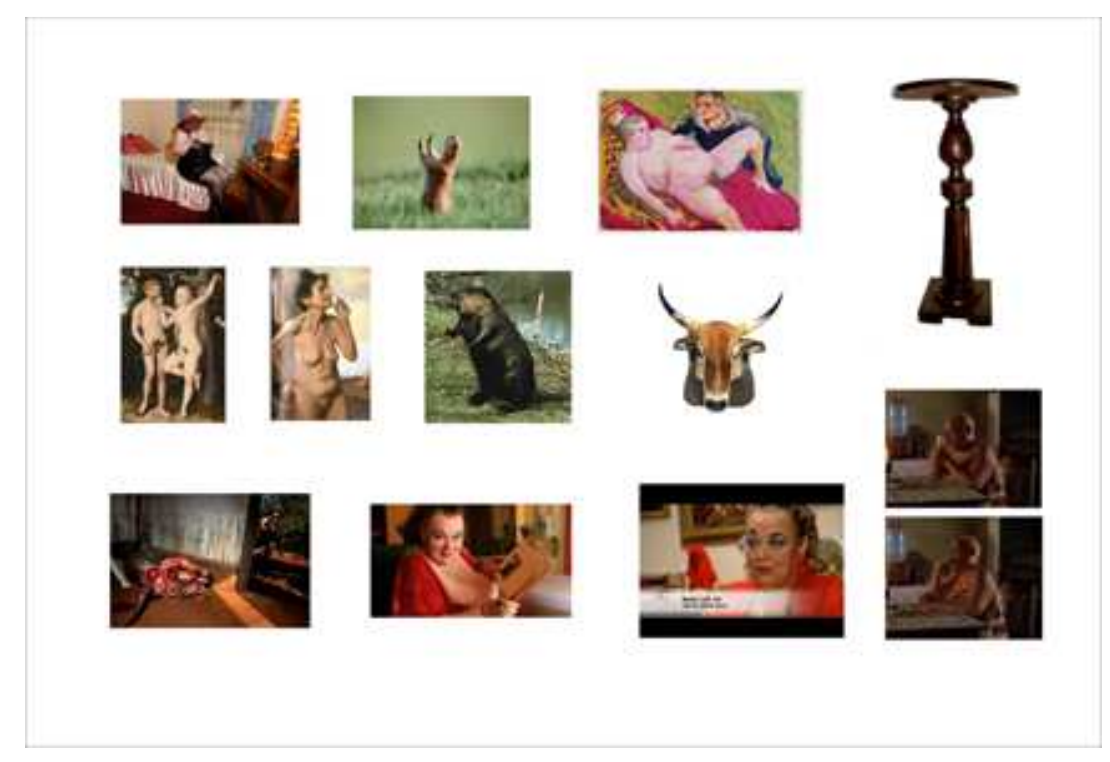

Fig. 4

$\mathrm{Na}$ figura 4, com imagens retiradas do meu Atlas de referências imagéticas, vemos mulheres velhas, pelancudas, com varizes nas pernas e provavelmente com dentes podres. Em seguida, representando o alfabeto de bichos usado pelo poeta, temos lontras e uma cabeça de boi. Essas imagens me remeteram a outras de taxidermia, animais empalhados, cheiro de formol, poeira e material orgânico em estado de conservação. E me sugeriram um ambiente lúgubre e decadente. É necessário reconhecer o que nós procuramos, pois, em uma pesquisa em artes (BRITES; TESSLER, 2002, p.125), sabemos que o nosso objeto de pesquisa é construído durante o processo. 


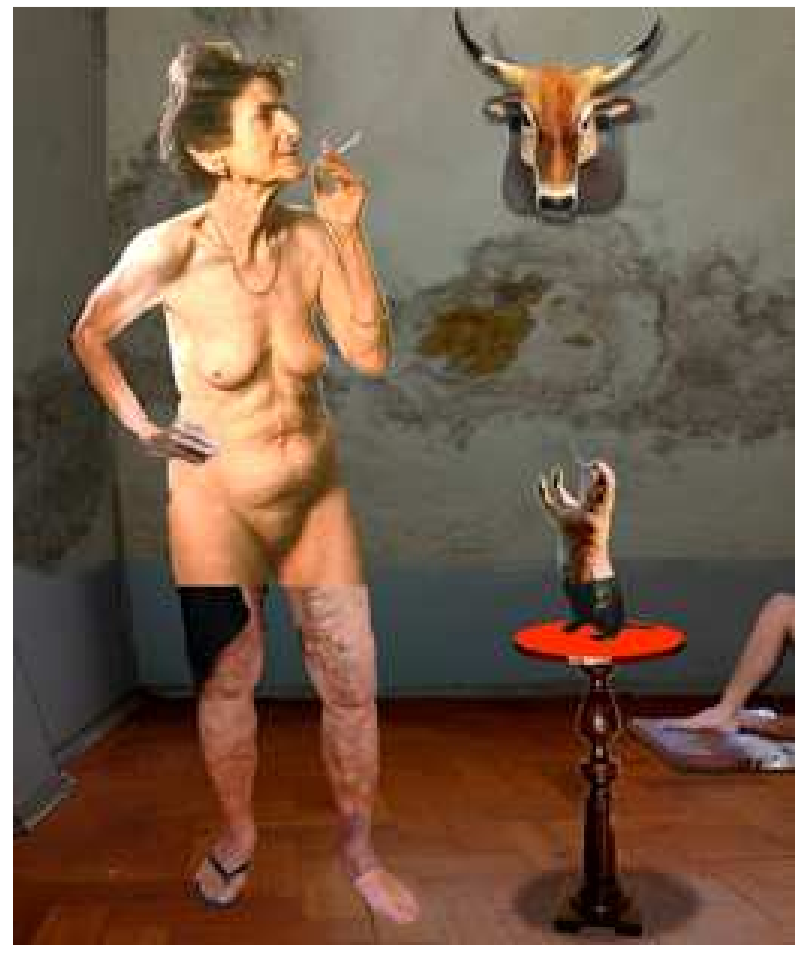

Fig. 5

Depois da apropriação das imagens e da construção do arquivo a ser utilizado no projeto, passamos à segunda fase: ressignificar as imagens utilizando o programa de computador Photoshop. Cada elemento das composições transformou-se em outra coisa. Algo totalmente inédito. O que vemos acima é uma dessas colagens digitais. Nela vemos as fotos apropriadas do Atlas e retrabalhadas em outro contexto. A começar pelo cenário, que ganhou paredes mofadas e descascadas. Outras paredes foram desenhadas. Duas lontras diferentes foram usadas para compor uma lontra na mesma posição do poema. Uma mesinha antiga foi utilizada para colocar a lontra e a perspectiva dessa mesinha também foi alterada no computador para se adequar ao ângulo da composição. Uma cabeça de boi empalhada foi posicionada na parede.

Esse esboço, produzido a partir do poema pela técnica da colagem digital, gerou outro produto, que foi uma pintura. Podemos, então, identificar as várias fases 
de representação: primeiro o objeto real, que foi fotografado e tornou-se outra coisa - transformou-se em uma foto. Depois essa foto foi apropriada e transformou-se em uma colagem, dando outra significação a esses elementos. A seguir essa colagem gerou uma pintura, chegando ao nível da ficção. Tudo isso pensando que o ponto de partida foi o poema. Com a pintura chegamos ao quinto grau da tradução. Assim, podemos verificar toda a trajetória da transmutação de um meio verbal para um meio visual e do imaterial para o meio material.

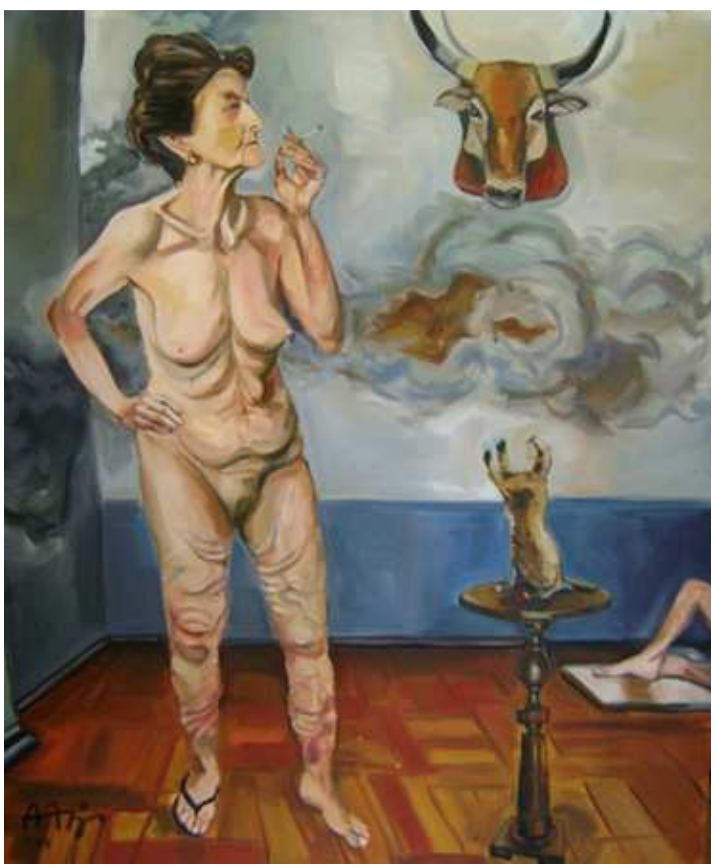

Fig. 6

Nessa tradução, trabalhei plasticamente com base na tradição da pintura expressionista alemã. Venho pesquisando o expressionismo há muitos anos. Pesquiso seus artistas, como Otto Dix e George Groz, com o detalhamento de uma lupa, ou seja, procuro estudar com minúcias não só a parte prática de seus procedimentos, mas busco também o conhecimento teórico sobre esses artistas. 
Dessa forma, interessa-me como as obras desses artistas se articulam com os conceitos de certas manifestações da cultura, procurando assim fazer um elo entre as produções contemporâneas e a História da Arte.

Nas pesquisas constatatamos que as temáticas do Expressionismo se relacionam diretamente com a obra de Sebastião Nunes. E estética do movimento também transmite, como em sua poesia, uma atmosfera densa e grotesca. O que nos fez relacionar os poemas de Nunes com o movimento Expressionista alemão foi a grande quantidade de obras em que aparecem personagens grotescos, prostitutas, sexo e violência. Na maioria das vezes as pinturas expressionistas trazem personagens desvalidos, bêbados, trabalhadores desempregados... A temática e a estética dos marginalizados.

\section{Segunda tradução canção desajeitada-colagem digital}

Analisaremos agora outra tradução da mesma poesia. Dessa vez trabalhei com a foto montagem. Foquei apenas na citação: "Antes da queda, Adão trepava mas não gozava". 


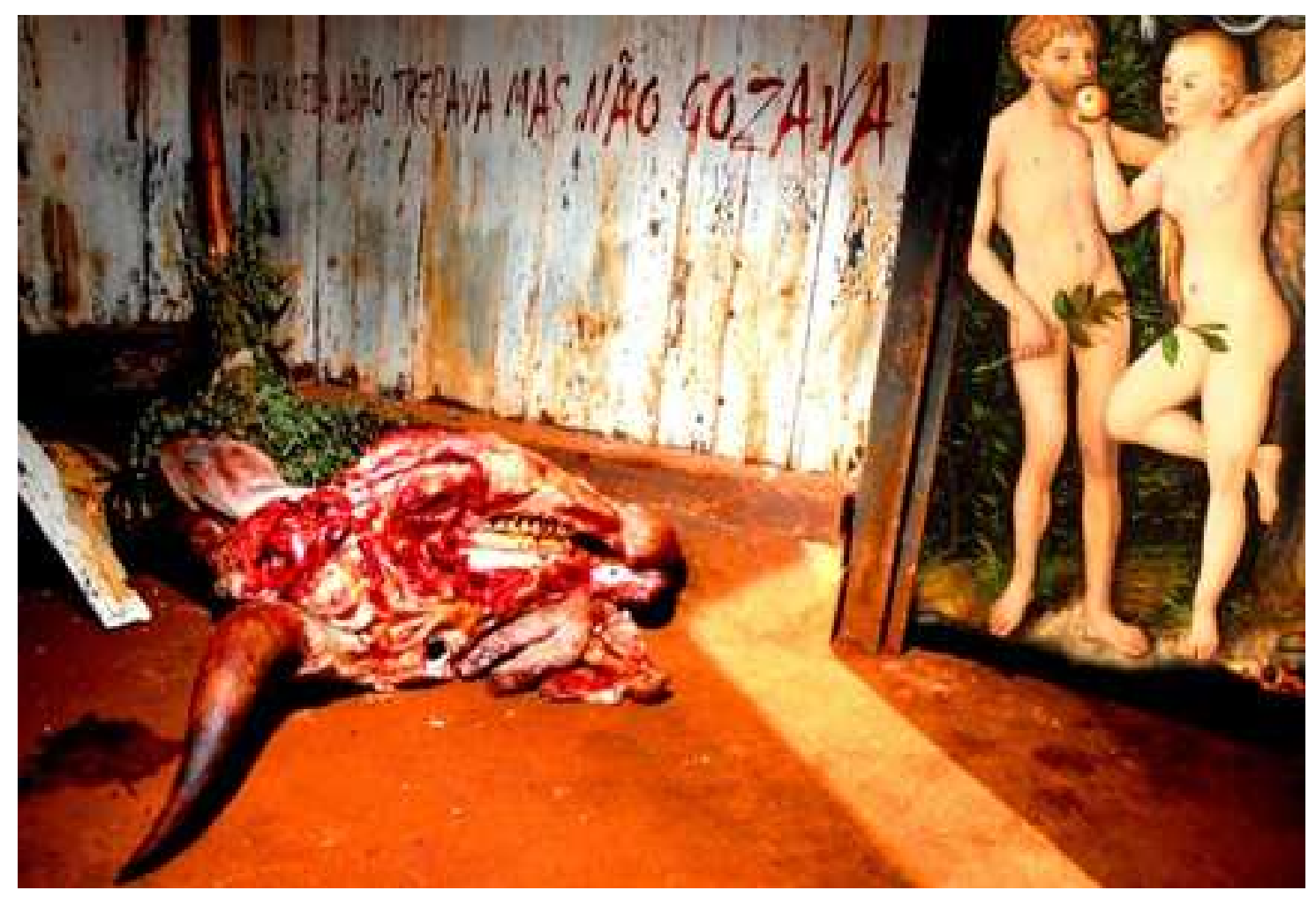

Fig. 7

Podemos observar os elementos usados nessa colagem:

Uma carcaça de cabeça de boi representando a queda de Adão: a carne do boi pode ser interpretada como o próprio sacrifício de Adão que, ao trair a promessa feita a Deus, foi castigado com a expulsão do paraíso (ver fig.7). A cabeça de boi foi usada nessa tradução como forma de representar a letra "T" do alfabeto dos bichos usado por Nunes nesse poema "Canção desajeitada". É a figuração animalizada da letra "T" representada por uma cabeça de boi e um castor em sua base (ver fig.1). Essa cabeça de boi na tradução anterior (fig. 6) foi representada por uma cabeça de boi empalhada na parede. Nessa tradução (fig. 7), a cabeça do boi está representada pela carcaça que restou, o que foi descartado da taxidermia da cabeça de boi da tradução anterior. Para se realizar uma taxidermia retiram-se todas as entranhas, substitui-se por um molde de 
crânio de resina e completa-se com palha. Como em Soutine, Rembrandt e Bacon a vianda ou a carcaça de carne de um animal sempre foi utilizada para representar a piedade. Podemos constatar que a vianda é utilizada nos mais altos patamares da tradição da pintura ocidental. Segundo Deleuze:

A vianda não é uma carne morta, ela guarda todos os sofrimentos e toma sobre si as cores da carne viva. Um tanto de cor convulsiva e de vulnerabilidade, mas também de invenção sedutora, de cor e de acrobacia. (DELEUZE, 2007, p.12)

Podemos também relacionar a imagem do bovino da letra "T" do poema com a imagem da vaca. A vaca no dicionário de símbolos representa a imagem do materno, da fertilidade e da renovação. A fertilidade que está ligada ao caráter sexual. Ou podemos também pensar na imagem do touro que é o símbolo da fecundidade. Na mitologia grega Júpiter teve relação sexual com Deméter, a deusa da fecundidade, sob a forma de um touro. Outro fator importante nessa análise é o fato de se tratar de um bovino, e os bovinos são animais que tem 4 estômagos, ou melhor, um estômago peculiar com quatro cavidades. Essas vísceras e entranhas representadas pelo baixo-ventre adquirem um caráter sexual. Também pensando no baixo-ventre, podemos observar o formato do desenho da letra " $T$ " do alfabeto de bichos e sua relação com o órgão sexual feminino. Notemos também que o local onde o castor põe a boca pode ser associado à imagem da entrada da vagina. 


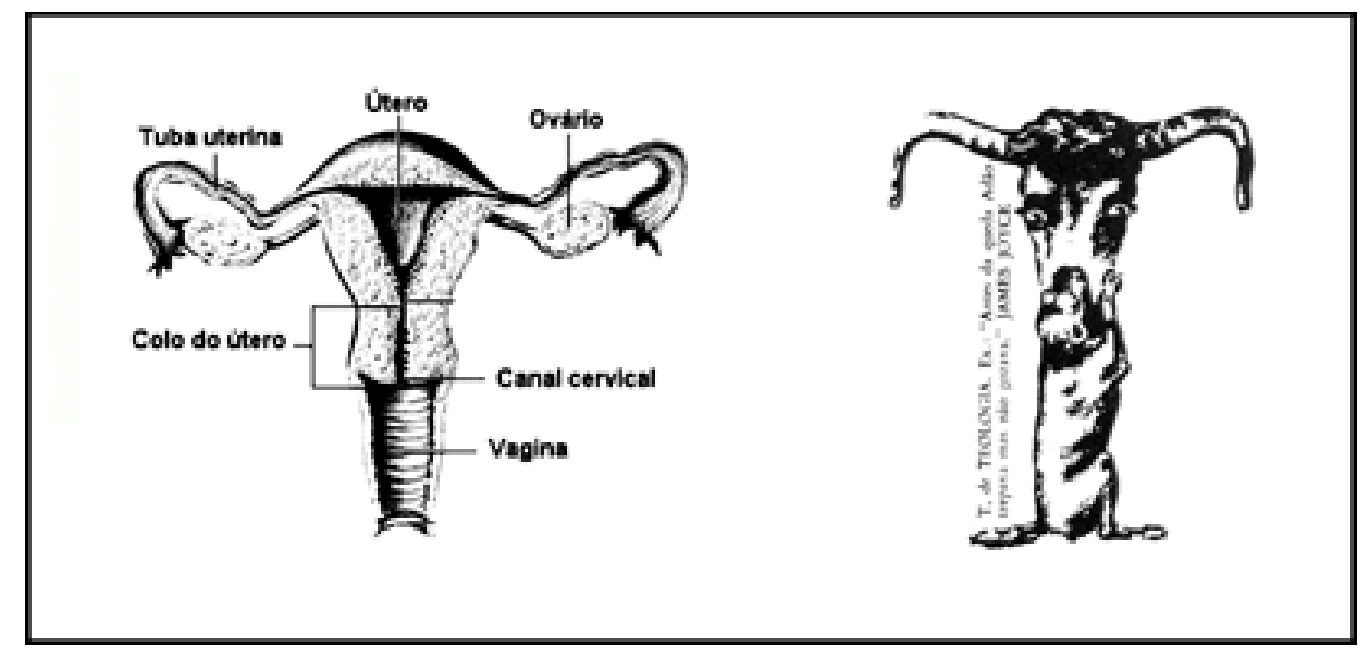

Fig. 8

$\mathrm{Na}$ parede em frente à carcaça (fig. 7) do boi, vemos uma frase com letras manuscritas como se molhadas no sangue da carcaça que escorre no chão. Essa cena acontece dentro de um cômodo de chão de terra batida e com paredes desgastadas e sujas. Do lado de fora do barraco, vemos a figura de Adão e Eva no momento da sedução do pecado. Eva aparece com uma expressão bem sedutora ao lado da cobra, que representa a figura do diabo, oferecendo uma maçã para Adão. Esse olha para o outro lado e tem um semblante de se deixar seduzir, porém não parece gozar de prazeres com esse ato. A imagem de Adão e Eva é uma pintura de Lucas Cranach, "o Velho" (14721553), que estudou com Mathias Grünewald, um dos pintores germânicos precursores do Expressionismo.

Essas apropriações fazem um diálogo direto com os procedimentos de Sebastião Nunes que usa imagens dos mais diversos meios. Também a utilização da pintura de Cranach faz uma referência à tradição da pintura alemã, utilizada nessa pesquisa. Certamente essa cabeça de boi sem o couro, descartada de uma taxidermia, será posteriormente utilizada também como 
modelo de uma pintura. Busquei nessa imagem a vulnerabilidade e a sedução das cores da carne viva como em Francis Bacon e Chain Soutine.

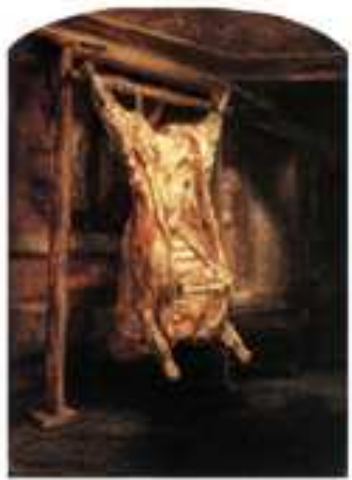

Rembrandt

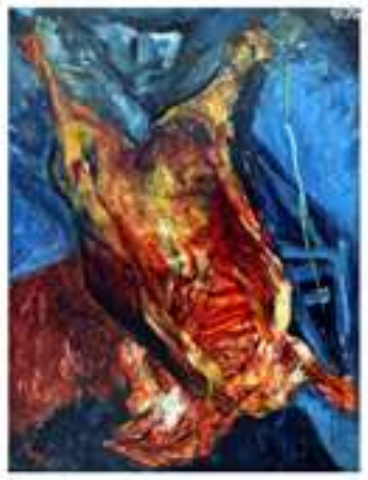

Soutine

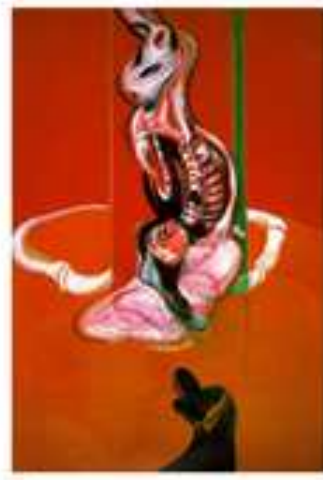

Bacon

Fig. 9

\section{Terceira tradução canção desajeitada-vídeo animação}

$\mathrm{Na}$ terceira tradução desse poema, usamos o suporte digital: o vídeo e o computador.

Para produzir a animação utilizamos imagens em movimento apropriadas de um filme de Cláudio Assis, O Baixio das Bestas. O filme em questão é representação da vida grotesca. Seus personagens são o retrado da escória humana, o viver no limite, a vida à margem. $O$ grotesco apresentado no filme de Assis emparelha-se com o grotesco apresentado por Nunes na poesia "canção desajeitada". Esses frames, ou fotogramas do filme, foram transportados para o computador e retrabalhados com a técnica de carvão sobre papel. Segue o storyboard da animação:

(story-board é uma sequência de quadros onde são colocadas as cenas da forma como imaginadas pelo diretor. Um planejamento para pré-visualizar um filme ou animação). 


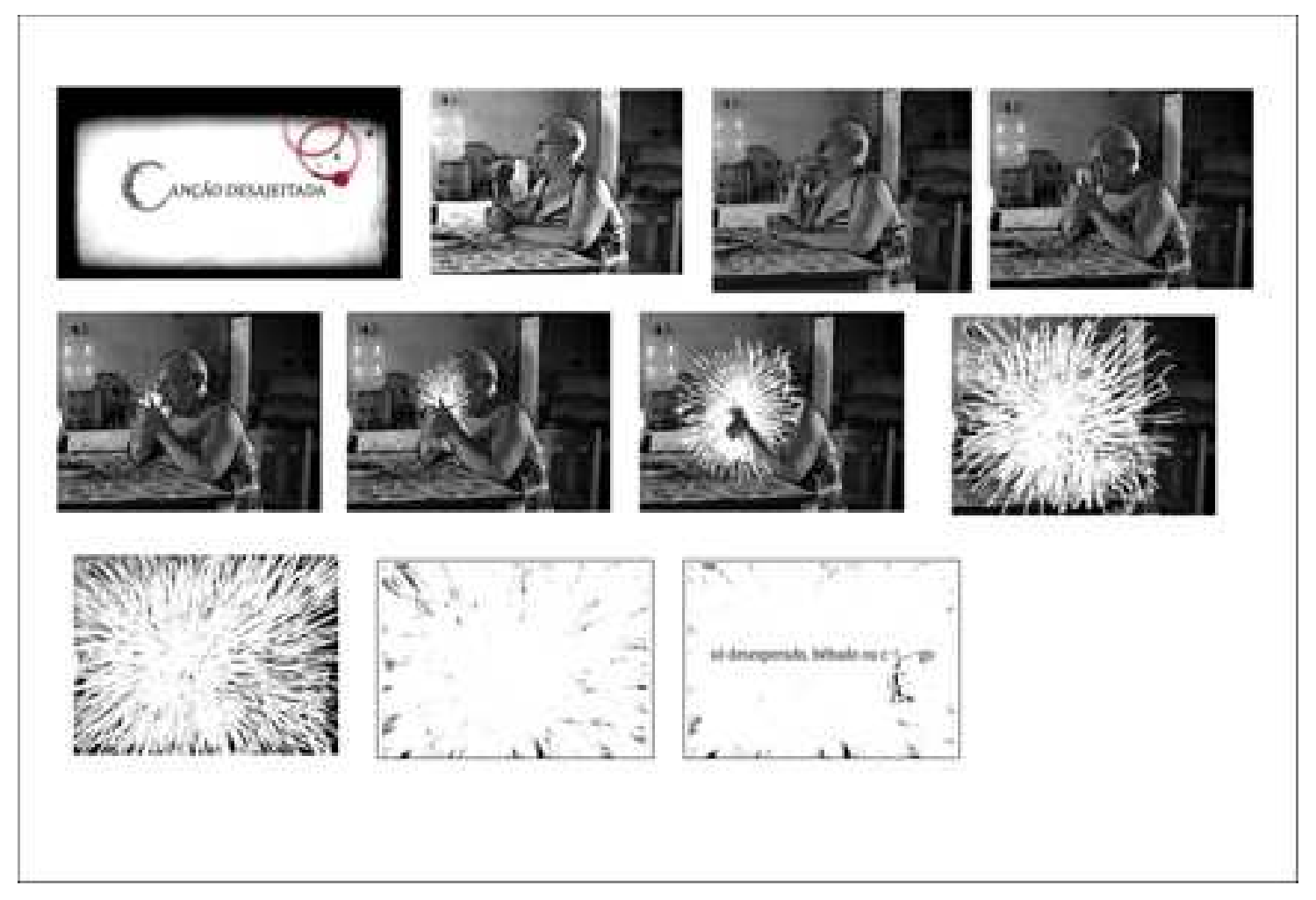

Fig. 10

O filme "O Baixio das Bestas" já nos era conhecido bem antes de começarmos esta pesquisa, que resultou na dissertação de mestrado "O AMOR É UM CÃO MAMALUCO: A imagem do amor na poesia de Sebastião Nunes e Charles Bukowski" (2013). E muitas cenas fazem parte do nosso acervo de imagens da memória. Podemos dizer que o trabalho do artista começa bem antes que ele coloque a mão na massa. Deleuze afirma que:

é um erro dizer que o pintor está diante de uma superfície branca. A crença figurativa advém desse engano: de fato se o pintor estivesse diante de uma superfície branca ela poderia reproduzir um objeto exterior que funcionasse como modelo. Mas não é assim. O pintor tem muita coisa na cabeça, ou a sua volta, ou no atelier. Portanto tudo que há na sua cabeça ou a sua volta já está na tela, mais ou menos virtualmente, mais ou menos atualmente, antes que ele comece a trabalhar. (DELEUZE, 2007, p.45). 
De fato, ao começar um trabalho de criação plástica, seja um quadro, um desenho, uma gravura ou uma animação, o artista recorre à sua bagagem imagética. É muito importante para um artista a construção de um arquivo permanente de imagens. A constituição de arquivos é muito praticada na arte contemporânea, a exemplo do pintor alemão neoexpressionista Gerard Richtercomo nos explica Sandra Rey ao falar de Richter e seu Atlas:

\begin{abstract}
que acumulou, durante anos, imagens que funcionam como fontes potenciais para suas pinturas. Ele reúne essas imagens em uma certa ordem, em painéis. Essa coleção nomeada "Atlas", é um grande depósito de imagens à disposição dos projetos do artista. Ele contém , em sua maioria, instantâneos de amador, assim como reproduções de jornais, e de revistas populares. São acrescentados a essas categorias um grande número de retratos pornográficos e de fotos de figuras históricas e de acontecimentos celebres, como os sobreviventes dos campos de concentração de Hitler, entre outros. (REY, 2010)
\end{abstract}

Como no Atlas de Richter, o Atlas desta pesquisa não segue nenhuma lógica nem nenhuma ordem pré-concebida. São fragmentos do mundo colecionados como resquícios que contém uma potencialidade de um dia servir à criação de um trabalho. São referências guardadas em um arquivo de imagens que vivem em estado de latência. A qualquer momento podem ser convocadas e ressignificadas.

Nessa tradução para o suporte de vídeo, podemos ver no storyboard (fig. 10) uma tela de abertura em que aparece o título do poema "Canção desajeitada". Como no poema de Nunes, usei a mesma letra " $\mathrm{C}$ " do alfabeto ornamental com a mesma fonte usada pelo poeta ao compor seu poema. Imediatamente veio a lembrança dessa cena do filme onde essa mulher, velha, pelancuda, com varizes nas pernas, senta-se em uma mesa na zona boêmia, em um lugar inóspito no interior do Brasil. Tira um cigarro do seio, que provavelmente "tem tanta pelanca", olha para o nada com um olhar vago e esperançoso e acende o cigarro. A luz que emana da chama do isqueiro vai crescendo e toma toda a tela como se cegasse o espectador. Então aparece no branco da tela a parte final do 
poema: "só desesperado, bêbado ou cego." Na palavra "cego" usei a mesma letra "E" do alfabeto de pessoas (fig. 11) usada por Nunes em seu poema. Trabalhando com os elementos originais do poeta estabeleci uma ligação de equivalência imagética na abertura e no final do poema (fig.1):

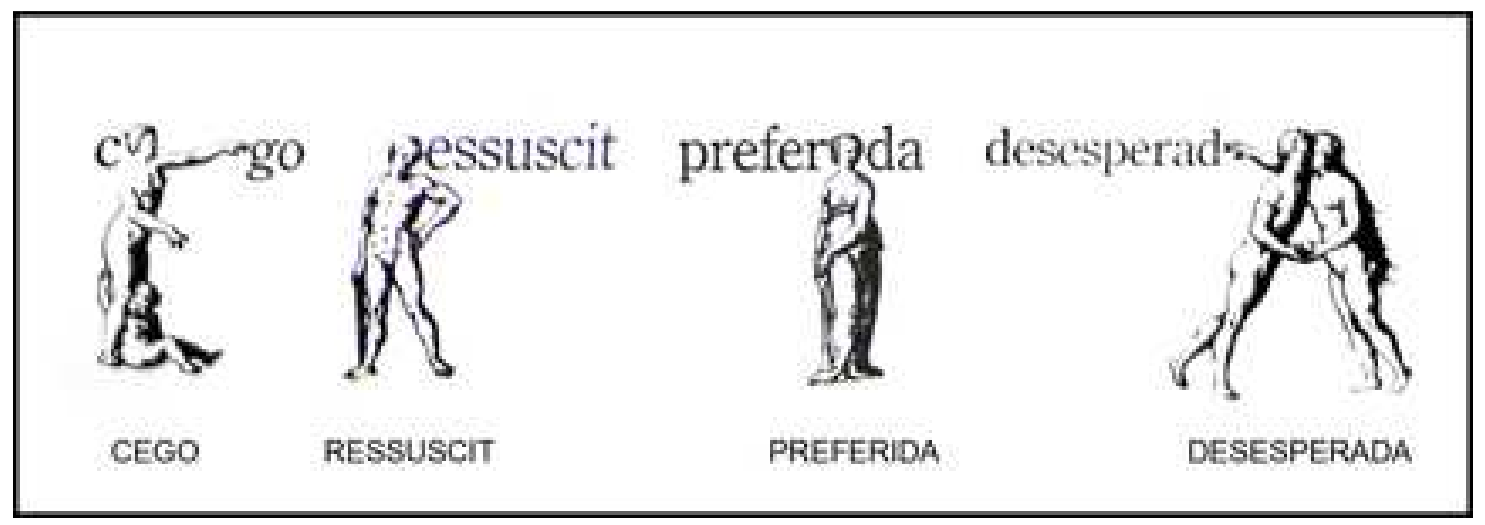

Fig.11

\section{As influências de diferentes meios na tradução de um mesmo poema}

Cada meio, ou suporte utilizado na tradução, determina como será o trabalho. Como disse Julio Plaza: "A comunicação permite que os fins justifiquem os meios, enquanto a arte permite que os meios justifiquem os fins." (PLAZA, 2003, p.66) Ou seja, são os meios utilizados para produzir um trabalho artístico que definirão como ele será ao final. $O$ artista deve dominar as técnicas para que ele possa transitar livremente por diversas linguagens, e assim optar por qual será a melhor para determinada expressão. Julio Plaza afirma que a reescrita criativa ou a:

Tradução Intersemiótica se pauta, então, pelo uso material dos suportes, cujas qualidades e estruturas são interpretantes dos signos que absorvem, servindo como interfaces. Sendo assim, o operar tradutor, para nós, é mais do que a "interpretação de signos linguísticos." Nossa visão diz mais respeito 
às transmutações inter sígnicas do que exclusivamente à passagem de signos linguísticos para não linguísticos (PLAZA, 2003, p.67).

E sabemos também que essa transmutação de linguagens pouco tem a ver com a fidelidade, pois ela cria sua própria verdade e processa-se em um movimento de transformação. (PLAZA, 2003, p.1) Em arte não podemos pensar que um movimento artístico é uma evolução do outro. Um movimento é sempre uma transformação do anterior, por isso o que vale é o conceito de transformação anulando completamente a ideia de evolução. Como no caso de uma tradução intersemiótica, em que o que acontece é uma transmutação de um meio para outro sem a preocupação em ser fiel ao original.

Outro ponto de vista na produção sígnica, que visa a sua materialidade, é a distinção entre o autográfico e o alográfico. (PLAZA, 2003, p.50-51). Os caracteres de uma produção de caráter autográfico são aqueles em que o artista pode se expressar com traços pessoais, ou seja: autográfico vem de auto $=$ próprio, por si próprio. Os caracteres autográficos tendem a produzir os traços da pessoa que produz a obra. Como, por exemplo, a pintura que contém o traço do autor, desde o esboço até a sua finalização.

Já a arte alográfica, que vem de alo = outro, diferente, produz seus objetos dentro de sistemas de notação. Ou seja, a arte alográfica depende de uma equipe para ser produzida, por isso o sistema de notação serve como guia para a sua realização. Como é o caso de um filme, em que existe um roteiro e um storyboard para que o restante da equipe possa seguir a mesma ideia. Ou como a música, literatura, arquitetura entre outras artes. No caso da música, o autor pode criar uma melodia e anotá-la em sua partitura. Porém ele dependerá de uma equipe de músicos para realizá-la. Esses músicos devem seguir fielmente a partitura, pois caso contrário a obra não se instauraria. Segundo Plaza "o artista autográfico está menos limitado do que o alográfico ao inscrever e "expressar" sua diferença com traços pessoais." (PLAZA, 2003, p. 51) 
Para a primeira tradução do poema "Canção Desajeitada", em pintura, usei o suporte de tinta óleo sobre tela. Esse suporte permitiu-me, através do meu gesto, imprimir caracteres pessoais na obra. Conforme vimos, a pintura possui características típicas do meio artesanal, já que o produto é uma peça única, sem igual, autêntica. Na pintura o artista trabalha diretamente na materialidade da obra, corporificando sua imaginação. Ou seja, essa obra, resultante da tradução, contém características autográficas e essas características operam pela polissemia e pela ambiguidade de seus códigos. A textura da tinta e as pinceladas bruscas e grosseiras fazem uma analogia direta com a linguagem e atmosfera usadas pelo poeta. As cores empregadas, vivas e fortes, oferecem um sentido de peso transferindo ao leitor/observador certo imaginário trabalhado pelo poeta.

A segunda tradução, em montagem fotográfica, aconteceu concomitantemente com a primeira, em pintura, como se pode observar na página do caderno de esboços (fig. 2). Servindo do arquivo pessoal de imagens, recorremos a uma montagem fotográfica feita no computador no software Photoshop. Nota-se que, apesar de desaparecerem todos os códigos do poema, essa tradução mantém uma relação de equivalência muito forte com o original. Há uma predominância de caracteres alográficos nessa tradução, visto que são imagens e suportes já prontos: são imagens fotográficas trabalhadas em um programa de computador com recursos de fábrica, já pré-definidos. Apesar de todo o tratamento de imagens, reconfiguração de cores e reenquadramento das fotos, esse tipo de tradução não permite enxergar a individualidade do artista. O que está em questão nesse tipo de tradução é a reprodutibilidade técnica. Não se trata de uma peça única. Segundo Walter Benjamim, a obra de arte concebida em meio fotográfico perde sua aura, ou seja, perde seu caráter de unicidade, de culto. A fotografia tem um grande poder de exposição devido às suas características de reprodutibilidade técnica. Ela pode ser exposta em vários lugares ao mesmo tempo. 
Hoje não estamos falando de fotografia analógica, com o uso da película de filme. Estamos utilizando a fotografia digital, que hoje não tem um suporte definido. Além das formas tradicionais de exposição e suporte, como a impressão fotográfica em papel, a fotografia digital é um arquivo de códigos binários, e tanto pode ser exibida numa tela de computador como ser impressa em papel, ou projetada em uma parede de uma galeria ou outro suporte qualquer. Porém, a crítica de Benjamin à reprodutibilidade técnica é ainda procedente, e isso pode ser um ponto característico para esse tipo de tradução, pois ao quebrar o valor único da obra, quebramos sua aura e seu valor de culto. $E$, segundo Benjamin, "à medida que as obras de arte se emancipam do seu uso cultual, aumentam as ocasiões para que elas sejam expostas." (BENJAMIN, 2012, p.187).

Nota-se também que essa montagem fotográfica é um objeto híbrido, dotado de linguagem visual e verbal (fig.7). Como no poema original de Nunes, "Canção desajeitada", que contém a linguagem verbal e a não verbal, formando assim uma tensão entre imagem e texto. Devemos considerar também o caráter utilitário do texto. O texto em si pode ser visto como uma arte que opera sobre códigos alográficos (códigos verbais tradicionais), mas, ao mesmo tempo, ao transcrever o poema, foram registrados caracteres autográficos na obra. Mesmo utilizando uma fonte já pronta do computador ela foi trabalhada, disposta em perspectiva, com ferramentas de distorção e colorização para representar a textura e a transparência de sangue. Mesmo no meio digital, as intervenções operadas no computador dependem da criatividade do artista. Assim torna-se um suporte híbrido, uma vez que este partilha características dos suportes artesanais e características dos suportes mecânicos industriais.

A terceira tradução é em meio eletrônico: um vídeo animação. Esse vídeo animação foi concebido em uma construção coletiva e à priori contém características totalmente alográficas: a obra foi gerada pelo artista em uma interface digital com mediação de leis numéricas; outro profissional, um editor de 
imagens, usou um programa de edição chamado After Effects, manipulando as imagens concebidas pelo artista e as editou com base em um storyboard que serviu de guia para essa montagem. Novamente utilizamos o sistema de notação mencionado por Plaza.

A linguagem verbal do início do vídeo e do final (fig.10) também tem características alográficas visto que se trata de códigos verbais convencionais com uma equivalência direta, fazendo com que o leitor compreenda os legisígnos do poema original. Porém a técnica utilizada nessa tradução foi a técnica de rotoscopia, onde o filme serve como base para o desenho das cenas. Esses desenhos, feitos no Photoshop e retrabalhados usando a técnica de carvão sobre papel, também dão uma característica autográfica à tradução visto que não foi usado um filtro já pré-configurado do Photoshop e sim desenhos originais produzidos na mesa digitalizadora Wacom. Isso permitiu imprimir uma gestualidade bem pessoal e original ao trabalho. Além disso, para fazer a tradução em vídeo animação, desde o começo foram registrados caracteres autográficos do processo. Foi utilizado um caderno de esboços e construído um diário de ideias.

Podemos notar nas traduções deste poema que uma mesma tradução pode conter características autográficas e alográficas com determinadas proporções. Compreendemos assim, que tais características não são excludentes entre si. Além disso, as ligações artísticas ganham em intensidade com os procedimentos tecnológicos envolvidos em todo o processo. Estes devem ser identificados tanto na linguagem verbal, entendida como um fazer artístico singular, quanto nas traduções com suas respectivas execuções técnicas que estão permeadas pela ação de um sujeito criador. Este último deve ser compreendido como aquele que transita entre os meios diversos do tecnológico e do ato criativo seja sincrônica ou diacronicamente. 


\section{POETRY, ART AND TECHNOLOGY: \\ A DIALOGUE WITH THE IMAGE OF LOVE IN SEBASTIÃO NUNES}

ABSTRACT: This paper proposes a reflectionon the creative process from the relationships between verbal and non verbal in the context of poetic dialogues between art and poetry and intermediality, considering there's intersemiotic translations that allow us to discuss also aspects of technology. To do this we chose as study object the image of love in the poetry of Sebastião Nunes, specifically the book Antologias Mamalucas.

KEYWORDS: Visual arts. Poetry. Intermediality.

\section{REFERÊNCIAS}

BATAILLE, Georges. 0 erotismo. Trad. Antonio Carlos Viana. Porto alegre: L\&PM, 1987.

BENJAMIN, Walter. Charles Baudelaire um lírico no auge do capitalismo. Brasiliense-São Paulo. Primeira ed. 1989, terceira ed. 2010.

BENJAMIN, W. Magia e técnica, arte e política. Ensaios sobre literatura e história da cultura. Brasiliense - São Paulo - 8a edição - 2012.

BRITES, Blanca; TESSLER, Elida (Org.). O meio como ponto zero: metodologia da pesquisa em artesplásticas. Porto Alegre, Ed. Universidade/UFRGS, 2002. (Coleção Visualidade; 4.)

BUENO, A.; GÓES, F. O que é Geração Beat. São Paulo: Brasiliense, 1984.

CAMPOS, Geir. O que é tradução. São Paulo: Brasiliense, 1987.

CAPELLARI, Marcos Alexandre. 0 discurso da contracultura no Brasil: 0 underground através de Luiz Carlos Maciel. São Paulo: USP, 2008. (Tese Doutorado em História Social).

DELEUZE, Gilles. Francis Bacon: lógica da sensação. Trad. Roberto Machado et al. Rio de Janeiro: Zahar, 2007.

PLAZA, Julio. Arte, ciência e tecnologia. In: Processos criativos comos meios eletrônicos: poéticas digitais. São Paulo: Hucitec, 1998.

PLAZA, Julio. Tradução Intersemiótica. São Paulo: Perspectiva, 2003.

REY, Sandra. Caminhar: experiência estética, desdobramento virtual. Porto Arte, Porto Alegre, v. 17, n. 29, nov. 2010. Disponível em: <http://seer.ufrgs.br/PortoArte/article/view/23329>. 


\section{SITES CONSULTADOS:}

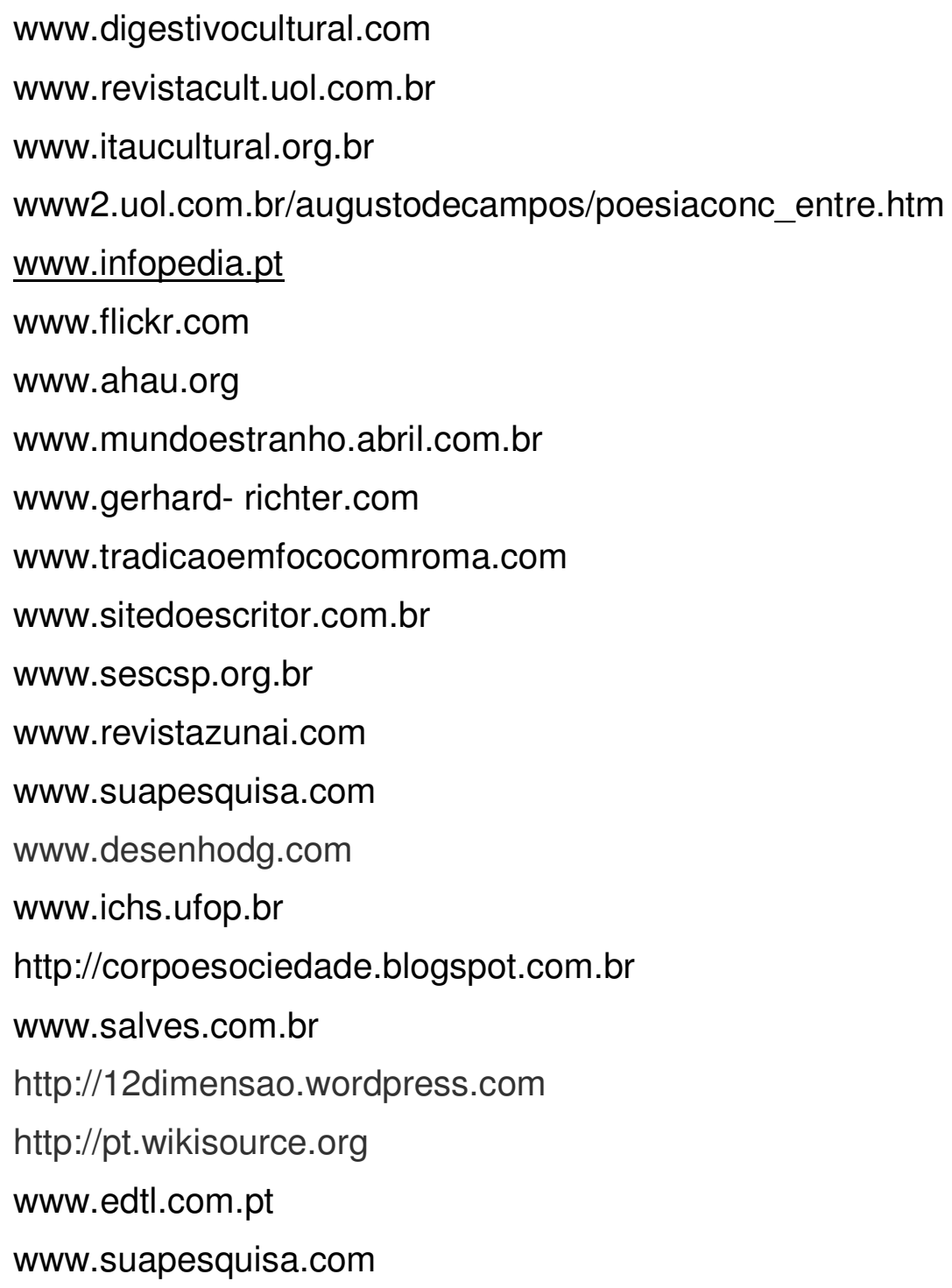

FILME:

Baixio das Bestas - 2006 - Cláudio Assis, Brasil.

Texto recebido em: 14/07/2014. 